\title{
A GÊNESE DA TRANSFERÊNCIA FREUDIANA: DO MODELO FÍSICO-QUÍMICO-ENERGÉTICO A UMA LEITURA METAPSICOLÓGICA
}

THE GENESIS OF FREUDIAN TRANSFER: FROM THE PHYSICOCHEMICAL-ENERGETIC MODEL TO A METAPSYCHOLOGICAL READING

LA GÉNESIS DE LA TRANSFERENCIA FREUDIANA: DEL MODELO FÍSICO-QUÍMICOENERGÉTICO A UNA LECTURA METAPSICOLÓGICA

\author{
Douglas Félix de Oliveira* \\ Luís Flávio Silva Couto** \\ Ricardo Luiz Alves Pimenta ${ }^{* * *}$
}

\begin{abstract}
RESUMO
O objetivo deste artigo é discorrer sobre pontos importantes da démarche de Freud na construção teórica da transferência. Busca-se, a partir do solo nativo de Freud, identificar a gênese do fenômeno da transferência, que, em seu horizonte clínico, tornou-se um de seus conceitos fundamentais. Para isso, recorreu-se à revisão bibliográfica para investigar a epistemologia do solo nativo de Freud, seus modelos bem como os referentes físico-químicoenergéticos. Tais modelos e referentes compuseram as bases do fundamento metodológico de Freud na construção da metapsicologia, que, por sua vez, tornou-se uma das referências para o entendimento do fenômeno da transferência. Este artigo pode contribuir com as pesquisas que envolvem a temática da transferência, pois sua gênese, seus modelos e os referentes aqui colocados estão localizados no solo nativo de Freud, indispensáveis à sua teorização.
\end{abstract}

Palavras-chave: Psicanálise. Epistemologia nativa de Freud. Metapsicologia. Transferência.

\footnotetext{
Texto recebido em 14 de outubro de 2017 e aprovado para publicação em 8 de maio de 2018.

Mestrando em Psicologia (Estudos Psicanalíticos) pela PUC Minas, especialista em Saúde Mental, psicólogo clínico, psicanalista. Endereço: Praça Dr. Augusto Gonçalves, 418, sala 605 - Edifício Maria Tereza, Itaúna-MG, Brasil. CEP: 35680-054. E-mail: douglas.psic@gmail.com.

* Pós-doutor em Psicanálise pela Université Paris 8, doutor em Filosofia pela Universidade Federal do Rio de Janeiro (UFRJ), membro de Escola Brasileira de Psicanálise - Seção Minas, filiada à Associação Mundial de Psicanálise, professor no Programa de Pós-Graduação e da Graduação da Pontifícia Universidade Católica de Minas Gerais (PUC Minas), psicólogo. E-mail: luisflaviocouto@terra.com.br.

${ }^{* * *}$ Mestre em Psicologia (Estudos Psicanalíticos) pela PUC Minas, especialista em Saúde Mental, membro fundador do Grupo de Estudos em Psicanálise (GEP), professor no Curso de Psicologia da Faculdade UNA, em Divinópolis-MG, psicólogo clínico, psicanalista. Endereço: Praça Dr. Augusto Gonçalves, 418, sala 605 - Edifício Maria Tereza, Itaúna-MG, Brasil. CEP: 35680054. E-mail: pimentapsi@yahoo.com.br.
} 


\begin{abstract}
This paper proposes to analyze essential points about Freud's demarche (mode of procedure) in the theoretical construction of transference. The aim, based on Freud's original ideas is to identify the origin of the transference phenomenon, which, in his clinical scenario, became one of his fundamental conceptions. For that purpose, a literature review was carried out to investigate the epistemology of Freud's ideas, his models as well as the physicochemical-energetic referents. Such models and referents constituted the structure of Freud's methodological foundation in the development of the metapsychology, which, in turn, became one of the references to understand the transference phenomenon. The present paper may contribute to the research processes approaching the transference topic as its origin, models, and referents displayed here are framed within Freud's original ideas, which are imperative to its theorization.
\end{abstract}

Keywords: Psychoanalysis. Freud's original epistemology. Metapsychology. Transference.

\title{
RESUMEN
}

El objetivo de este artículo es discurrir puntos importantes de la démarche de Freud en la construcción teórica de la transferencia. Se busca, en la perspectiva freudiana, identificar la génesis del fenómeno de la transferencia, que, en su horizonte clínico, se tornó uno de sus conceptos fundamentales. Para eso, se utilizó la revisión bibliográfica para investigar la epistemología de Freud, sus modelos, así como sus referentes físico-químico-energéticos. Esos modelos y referentes componen las bases del fundamento metodológico de Freud en la construcción de la metapsicología, que, por su vez, volvió una de las referencias para el entendimiento del fenómeno de la transferencia. Este artículo puede contribuir con las búsquedas que implican la temática de la transferencia, pues su génesis, sus modelos y los referentes aquí presentados están localizados en el suelo nativo de Freud, indispensables para su teorización.

Palabras clave: Psicoanálisis. Epistemología nativa de Freud. Metapsicología. Transferencia.

\section{INTRODUÇÃO}

E ste artigo tem o objetivo de discorrer sobre pontos importantes da démarche de Freud na construção teórica da transferência. Acredita-se que a compreensão da origem, dos rudimentos e das bases do fundamento metodológico de Freud permitiram um delineamento no que tange ao objeto desta investigação: 
a gênese da transferência freudiana: do modelo físico-químico-energético a uma leitura metapsicológica.

Por meio de revisão bibliográfica, investigou-se a epistemologia do solo nativo de Freud, seus modelos e os referentes físico-químico-energéticos que evidenciaram as bases do fundamento metodológico de Freud na construção da metapsicologia, que, por sua vez, tornou-se uma das referências para o entendimento da gênese da transferência.

Entende-se que todo saber científico tem seus rudimentos, seu regime, suas regras próprias de funcionamento, seus referentes específicos, o que possibilita elaboraçôes, produçōes e a própria constituição desse saber. Assoun (1983) ressalta a importância desses elementos, destacando a relevância de compreendêlos, se possível, na terra natal e na linguagem de origem do pesquisador, o que, para a pesquisa empreendida, não foi possível, limitando-nos às traduções em português, embora tenhamos colocado alguns conceitos em alemão, para maior precisão dos termos utilizados no artigo. Acredita-se que é na literalidade do discurso freudiano e na objetividade de seu meio que se deve procurar seu fundamento epistemológico (o que nos conduz a investigar sua prática científica), tendo em vista que Freud, desde o Projeto para uma Psicologia científica de (Freud, 1895/1970) ${ }^{1}$ até seus últimos escritos, apontou a Psicanálise, como toda teoria psicológica, como uma ciência natural (naturwissenschaft). Nesse projeto, Freud destaca que "toda teoria psicológica, independente do que se realiza do ponto de vista da ciência natural, precisa nos explicar tudo o que já conhecemos, da maneira mais enigmática, através de nossa 'consciência”' (p. 326). Nessa lógica, a teoria psicológica também terá de explicar, segundo Freud, o que não se sabe a respeito da pressuposição relativa a "quantidades e neurônios". Mais de 40 anos depois do Projeto, ele permanece com a mesma ideia, tendo-a recolocado inúmeras vezes. A afirmativa de que a Psicologia é uma Ciência Natural pode ser encontrada no texto Esboço de Psicanálise (Freud, 1938/1976), como também no texto Algumas liçôes elementares de Psicanálise (Freud, 1940/1970).

Dessa forma, em seu texto Esboço de Psicanálise, Freud (1938) afirma que a visão [da Psicanálise] de que o psiquismo "é inconsciente em si mesmo, capacitou a Psicologia a assumir seu lugar entre as ciências naturais como uma ciência" (p. 183). Nesse texto, Freud presume, de maneira ainda incerta, que, no aparelho psíquico, tal como proposto em outras ciências da natureza, esteja em ação alguma espécie de energia, talvez sob duas formas, uma livre e outra ligada, denominando-as de processo primário e processo secundário. Afirma que a hipótese por ele desenvolvida, da origem dos fenômenos da consciência, o coloca

1 A primeira data indica o ano de publicação da obra, e a segunda, a edição consultada pelo autor, a qual somente será pontuada na primeira citação da obra no texto. Nas seguintes, será registrada apenas a data de publicação original. 
na posição de "estabelecer a Psicologia em bases semelhantes às de qualquer outra ciência da natureza, tal como, por exemplo, a Física” (p. 225).

Já, em Algumas liçôes elementares de Psicanálise (Freud, 1940), ele afirma que a Psicanálise constitui uma parte da Ciência da Psicologia, e coloca a Psicologia como uma Ciência da Natureza. "Também a Psicologia é uma ciência natural. O que mais pode ser?” (p. 317).

Por essa razão, investiga-se o teor nativo de Freud e seus referentes epistêmicos que antecederam e prepararam a primeira teorização do conceito de transferência. Com Assoun (1983), destaca-se a importância da valorização desses referentes epistêmicos para a compreensão da fisionomia do saber psicanalítico.

Dessa forma, este artigo localizou a epistemologia rigorosamente nativa de Freud e de sua época, que se apresenta com forte teor físico-químico-energético. Essa epistemologia contribuiu para o delineamento das bases do fundamento metodológico de Freud na construção de sua metapsicologia, que se tornou uma das referências para o entendimento da transferência. Essa epistemologia serviu também de base para a compreensão da "transferência de sentido" no processo da formação dos sonhos, que, por sua vez, desvelou a dinâmica da transferência analítica. Entretanto, para o tratamento do tema desta investigação, optou-se em localizar pontos importantes da démarche de Freud na gênese da transferência.

Assim, optou-se por um estudo minucioso dos próprios textos de Freud que tratam prioritariamente dos referentes epistêmicos e dos rudimentos da transferência, tendo como apoio privilegiado a Introdução à epistemologia freudiana, de Assoun (1983). Utilizou-se também de outros autores que contribuíram na exploração da temática em questão, sempre privilegiando o solo nativo de Freud, e não releituras posteriores. Salienta-se que os estudos de Assoun (1983) estão presentes ao longo do texto, pois serviram de apoio para o entendimento dos referentes epistêmicos de Freud.

Para se atingirem os objetivos pretendidos, este artigo foi organizado em três sessōes: "A epistemologia nativa de Freud e seu modelo físico-químico", os "Rudimentos da transferência e referenciais metapsicológicos" e "A importância de Herbart e Fechner para a dinâmica representacional e para o inconsciente". 


\section{A EPISTEMOLOGIA NATIVA DE FREUD E SEU MODELO FÍSICO-QUÍMICO}

O desenvolvimento da Psicanálise freudiana originou muitas análises filosóficas em sua estrutura metodológica, o que evidenciou a importância de sua compreensão nativa. Barbelli (2008) salienta que essas análises filosóficas apresentam contribuições importantes em relação às Ciências Naturais, fato que suscita um problema para a Psicanálise, já que levou muitos estudiosos a negarem a sua cientificidade ou a restringi-la ao campo das Ciências Humanas.

Em decorrência disso, esta seção sinaliza a natureza epistemológica da Psicanálise freudiana, com o intuito de embasar a compreensão da gênese da transferência: seus rudimentos, seus modelos e as referências que antecederam suas primeiras teorizações.

Em termos históricos, Assoun (1983) aponta a importância do surgimento do Manual de Fisiologia humana, de Müller (1801-1858), que formulou a teoria da energia específica dos nervos que revolucionou a neurologia. É desse manual que surgiu a grande linhagem dos fisiologistas alemães, tais como Brücke e Helmholtz, entre outros. Essa linhagem de fisiologistas colocou-se em estreita relação com o desenvolvimento da Física. Eles chegaram à Física pela Medicina, mais precisamente, pela via da Fisiologia.

Para a Psicanálise de Freud, também são de grande importância como "grelhas de decifração" tanto o modelo de Brücke (1819-1892), que tem por base uma prática anátomo-fisiologista, quanto o modelo de Helmholtz (1821-1894), centrado na interseção da Física com a Fisiologia. Note-se que esses podem ser pautados em origens mecanicistas, anátomo-fisiologistas e físico-químicoenergéticas provindas da Fisiologia, e realizados na Alemanha, nas décadas de 1830 a 1840. A Psicologia, contudo, surge como a quarta estação nesse trajeto.

Quanto à Freud, pode-se dizer que ele assimilou tais modelos para a construção de seu método, pois deles extraiu elementos consoantes com o rigor de sua época. Em Um estudo autobiográfico, Freud (1925/1970) declarou que foi no laboratório de Fisiologia de Brücke que, finalmente, encontrou o repouso e a plena satisfação. Vale ressaltar que, para Brücke, a Fisiologia é uma extensão da Física. Ela tem por objetivo tanto o estudo dos sistemas físico-químicos particulares quanto dos organismos dotados de propriedades especiais, entre as quais a faculdade de assimilação. Nessa direção, Assoun (1983) esclarece que o fisiólogo é o físico dos organismos. "Aquilo que unifica esses campos é o princípio de conservação da energia, em virtude do qual a soma das forças permanece constante em todo sistema isolado" (Assoun, 1983, p. 116). 
É importante lembrar-se desta linhagem para se compreender a passagem freudiana da Medicina à Psicologia. Ela é caracterizada pelo interesse permanente de Freud pela Física e pelo fascínio pela Fisiologia anatômica, tomadas como solo nativo, o humus que caracteriza a sua formação. Para Assoun (1983), tais modelos encontram-se ligados a nomes próprios porque difundem-se a partir de seus protagonistas. Entretanto Freud não os imita. Pelo contrário, aplica os modelos em sua prática, pois a ela estão, de certa forma, integrados.

Ressalta-se que foi nesse solo que Freud, em seu horizonte, remontou e reatualizou um circuito epistêmico que se instaurou nesse contexto e produziu adiante os elementos inéditos de seu objeto, a metapsicologia e a sua constituição. Porém o uso desses princípios não o constituiu como discípulo de Helmholtz ou de Brücke. Por meio de seus constructos, inaugurou uma nova metodologia: aplicou os princípios desses autores, empiricamente, aos fenômenos psíquicos, privilegiando-os diante da anatomia. Nessa direção, a emergência da Psicanálise freudiana sustentou sua investigação sobre a interferência do psiquismo no funcionamento do organismo. Nesse sentido, considera-se que os desafios da psicofisiologia a partir da década de 1840 , em sua vivacidade, atesta a atualidade persistente, mesmo nas décadas de 1880 e 1890, momento em que Freud começa sua carreira, da grande querela que havia dividido os nativistas e os empiristas: o organismo humano compunha o psiquismo ou era algo externo a ele? No cenário em que o orgânico e o psíquico estavam constantemente em pauta, dadas suas interrogaçôes monistas e dualistas, Freud herda desafios que perdurarão por longo tempo em sua reflexão. Até em suas últimas considerações sobre o aparelho psíquico, pode-se encontrar o traço dessa clivagem inscrita pelo nativismo e pelo empirismo.

Todavia a peculiaridade de Freud foi a de dedicar-se à concepção do psiquismo, alinhando-o ao campo físico-químico, seu modelo inconteste, que imprimiu na Psicanálise o seu caráter genuinamente científico. Salienta-se, no entanto, que Freud não ignorou o termo ciência do espírito (Geistewissenschaft), pois, quando mencionou a dualidade orgânico-psíquico, foi somente para confirmar a pertinência da Psicologia à família das Ciências Naturais.

Dessa maneira, Freud não restringe a Ciência da Natureza ao rigor do fisicalismo radical, impondo que somente as forças físicas e químicas, com a exclusão de quaisquer outras, agem no organismo. Para ele, a Psicanálise encontrase e permanece inteiramente do lado da esfera da natureza, o que permitiu a ela extrair um quinhão energético, um quantum, que brota no orgânico e é reconhecido no psíquico - pulsão (Trieb) - delineando o inédito de seu objeto: a metapsicologia. Freud sustentou que, embora a dualidade orgânico/psíquico seja irredutível, os processos que se dão em ambas as dimensões são concebidos em 
termos mecanicistas oriundos de forças e energias, sendo, pois, concebidos na dimensão físico-química. Essa dimensão revela a démarche de Freud na construção de seu método de investigação de acesso ao psiquismo, a metapsicologia, que atestou sua originalidade.

Como efeito de tal diligência, estabeleceu-se uma relação entre a Psicanálise, a Física e a Química. No texto Linhas de progresso na terapia psicanalítica, Freud (1919/1970, pp. 201-202) aponta essa relação e, nesse mesmo texto, faz uma analogia entre o trabalho do químico e o do analista. Ele ressalta que os sintomas e as manifestações patológicas do paciente bem como todas as suas atividades mentais são de natureza altamente complexa, e que, no fundo, os elementos desse composto são motivados pelos impulsos instintuais. Uma vez que o paciente não tem consciência dos motivos elementares, ou não os conhece em profundidade, o analista deve conduzi-lo à compreensão da composição de suas formações mentais complexas, associando os sintomas às moções pulsionais (Triebregungen) que os motivaram. O analista, assim, age como um químico, "como o químico que isola a substância fundamental, o 'elemento' químico, do sal em que ele se combinara com outros elementos e no qual era irreconhecível" (Freud, 1919, p. 202).

Freud (1919) adverte, entretanto, que a comparação com a análise química também apresenta limitações, pois, na vida mental, temos de lidar com tendências que estão sob uma compulsão para unificar e combinar. Nessa lógica, quando se analisa um sintoma em seus elementos, liberando um impulso instintual de um vínculo, ele não permanece isolado. Ao contrário, por meio de forças e energias, produz uma nova ligação. Como na análise química, "simultaneamente ao isolamento dos vários elementos, induzido pelo químico, surgem sínteses que não fazem parte da sua intenção, devido à liberação das afinidades eletivas das substâncias em questão" (Freud, 1919, p. 203).

Também no texto Uma dificuldade no caminho da Psicanálise, Freud (1917/1970) faz referência a essa analogia, desta vez agregando a divisão do trabalho entre a Física e a Química. Ali ele aponta que "a nossa parcialidade é como a do químico, que atribui a todos os componentes a força da atração química. Nem por isso está negando a força da gravidade; deixa que o físico lide com ela" (Freud, 1917, p. 172).

Nesse contexto, há ainda um questionamento feito por Freud (1914/1970), em seu texto Observaçôes sobre o amor transferencial: novas recomendaçôes sobre a técnica da Psicanálise III, que ilustra e relaciona o ofício do psicanalista com o do químico: ambos trabalham com forças explosivas, o que requer a cautela de um químico. Mas pergunta: "Quando foram os químicos proibidos, devido ao 
perigo, de manejar substâncias explosivas, que são indispensáveis, por causa de seus efeitos? (Freud, 1914, p. 221). Em Inibiçôes, sintomas e ansiedade, Freud (1926/1976) volta a falar de distribuição de forças na busca da satisfação, apontando que o temido resultado final pode ter o efeito de "paralisar a vontade do ego, e que, em toda decisão que tem de tomar, é quase tão fortemente impelido de um lado como do outro" (p. 141).

Quanto à Química, Freud (1920/1970), em seu texto Além do princípio de prazer, formula a hipótese de que a substância viva, nos primórdios de seu surgimento, encontra-se dividida em pequenas partículas, que, desde então, se esforçam por reunir-se por meio das pulsões sexuais nas quais "a afinidade química da matéria inanimada persistiu” (p. 79). Se a Química serve para determinar a matéria da Psicanálise, a Física serve para esquematizar sua identidade epistêmica, seu modo de construção. Portanto se concorda com as reflexões de Assoun (1983), pois é dessa forma que se pode, seguindo indicações insistentes de Freud, abordar a genealogia de sua identidade e do inédito de seu objeto: a metapsicologia.

Pelos modelos físico-químico-energéticos fornecidos pelas Ciências da Natureza e de seus referentes epistêmicos, pôde-se detectar as teses fundamentais que estruturaram o pensamento freudiano. Todavia, sobre o fundo dessas teses prévias, destaca-se a emergência do inédito do objeto, a metapsicologia. Esta surge na trama da conformidade das linguagens nativas, indicando sua contribuição para o entendimento da gênese da transferência.

\section{RUDIMENTOS DA TRANSFERENNCIA E REFERENCIAIS METAPSICOLÓGICOS}

Sabe-se que a transferência está no cerne do debate sobre a especificidade do método psicanalítico que marcou a démarche de Freud no seu percurso teórico-clínico. Para investigar os rudimentos da transferência, faz-se necessário elucidá-la na história do movimento psicanalítico bem como buscar a sua gênese, por meio do histórico de seus elementos referenciais. Em sua trajetória, Freud "parece ler em dois registros: na teoria anatomopatológica do cérebro e na clínica" (Assoun, 1983, pp. 134-135). Esse percurso se realizou no interior do movimento histórico, do qual o saber analítico se constituiu em termos clínicos.

Verifica-se uma primeira descrição do fenômeno da transferência nos Estudos sobre a histeria (1893-1895), atrelada aos fundamentos da metapsicologia, localizados tanto nas Publicaçôes pré-psicanalíticas e Esboços inéditos (1886-1899), como, também, no texto A interpretação dos sonhos (Freud, 1900/1970). 
Em tais textos e contextos, verifica-se a transferência como categoria energética do aparelho psíquico bem como a lógica da etiologia das neuroses, que justificam a reformulação da ideia de trauma e esclarecem o papel da fantasia e dos componentes sexuais na constituição dos sintomas. Verifica-se, também, a transferência como núcleo do processo de formação dos sonhos, o que possibilita retratar a relação da memória e a atualização do desejo inconsciente. Essa atualização somente se faz possível na transformação de representantes substitutos (disfarçados) para serem aceitos pela consciência. Rabêlo, Veras Filho, Danziato, \& Quadros (2017) destacam que o uso do termo transferência nesse contexto contribuiu para a descrição dos fenômenos que antecederam e prepararam sua conceituação mais precisa.

Uma primeira descrição clínica do fenômeno da transferência pode ser vista nos Estudos sobre a histeria (1893-1895). Ali, Freud a define como uma tendência por parte do paciente em constituir uma falsa ligação ou conexão com o médico, um fenômeno pontual e contingente, característico da patologia da histeria. No capítulo A psicoterapia da histeria (Freud, 1893b/1970), Freud comenta um fragmento clínico no qual uma paciente transferiu para ele suas representações por meio de um sintoma histérico específico: o desejo de dar-lhe um beijo. Para Freud, ela relegara ao inconsciente esse desejo muitos anos antes, quando, em certa ocasião, um homem desejou dar-lhe um beijo. Freud registra que, ao fim de certa sessão, surgira nela um desejo semelhante em relação a ele, o que a deixou horrorizada. $\mathrm{Na}$ sessão seguinte, apesar de ela não recusar continuar o tratamento, apresentou uma resistência acentuada ao trabalho. "Depois de eu haver descoberto e removido o obstáculo, o trabalho prosseguiu. E, vejam só!, o desejo que tanto havia assustado a paciente surgiu como sua próxima lembrança patogênica” (Freud, 1893b, p. 292). Nesse fragmento clínico, Freud aponta que o conteúdo do desejo apareceu, antes de tudo, na consciência da paciente, sem qualquer lembrança das circunstâncias contingentes que o teriam atribuído a uma época passada. Essa falsa ligação (mésalliance) provocou o mesmo afeto (Affekt) que forçara a paciente, muito tempo antes, a repudiar esse desejo proibido.

Rabêlo et al. (2017) relatam que, apesar dessa descrição precoce, não foi possível extrair dela as consequências clínicas mais significativas que marcassem a discussão sobre a transferência na obra freudiana. Pode-se afirmar que, nessa época, faltaram ao horizonte de Freud os referenciais metapsicológicos que seriam básicos para que o fenômeno da transferência pudesse ser interrogado com base na perspectiva do psiquismo e sua dinâmica.

A formulação e a conceituação da transferência não são construídas de modo unívoco e lógico. Sua teorização acomete inicialmente diversos aspectos que compõem o fenômeno, valendo-se da metapsicologia, tal qual questionada nas 
Cartas 41 e 84 dirigidas a Fliess. Na Carta 41, de 13 de fevereiro de 1896, (Freud apud Masson, 1986) diz a Fliess que está ocupado com a Psicologia. Na verdade, afirma, "com a metapsicologia" (Masson, 1986, p. 173). Já na Carta 84, de 10 de março de 1898, ele questiona seriamente Fliess se ele, (Freud apud Masson, 1986), poderia usar o termo metapsicologia para a sua obra: "A propósito, vou perguntar-lhe a sério, se posso usar o nome de metapsicologia para minha psicologia que se estende para além da consciência” (Masson, 1986, p. 302). Assim, Freud integrou em conhecimentos específicos e codificados o estudo dos processos inconscientes que, enquanto transparecem nos fenômenos, constituem uma transobjetividade. Freud aprimorou sua teoria ante seu tempo e o mundo novo que emergiu, e produziu e efetivou o estudo do funcionamento do psiquismo: a metapsicologia.

Dessa forma, com a metapsicologia, nomeia-se a identidade epistêmica freudiana, cerne de sua originalidade. Destaca-se que Freud, sob o efeito das concepções físico-químicas de seu meio científico, construiu uma espécie de objeto, marcado com o selo do energetismo de seu tempo. Essa ideia, de uma investigação dos fenômenos psíquicos isomorfa em termos epistêmicos à dos fenômenos de tipo físico, sobrevive ao Projeto para uma Psicologia cientifica (Freud, 1895) e atravessa toda a concepção freudiana do saber metapsicológico.

Rabêlo et al. (2017) destacam também que um dos referenciais da metapsicologia que auxiliaram nos estudos do fenômeno da transferência foi o abandono da teoria da sedução em prol da ideia de fantasia, ou realidade psíquica, e o recalque (Verdrängung) que desponta como ação psíquica reguladora do trauma e como o principal mecanismo da etiologia das neuroses.

Tal mudança é apontada por (Freud apud Masson, 1986), em sua Carta 69 para Fliess, datada de 21 de setembro de 1897. Ali, ele afirma não mais acreditar em sua neurótica, isto é, em sua teoria das neuroses, que atribuía a causalidade da histeria à sedução de uma criança por um adulto. Diz Freud: "E agora quero confiar-lhe, de imediato, o grande segredo que foi despontando lentamente em mim nestes últimos meses. Não acredito mais em minha neurótica [teoria das neuroses]" (Masson, 1986, p. 265, grifo do autor). Destaca-se que essa mudança ocorreu concomitantemente à transformação da concepção de trauma. "A ideia de fantasia vem substituir a função que o trauma ocupava inicialmente na etiologia da histeria" (Rabêlo et al., 2017, p. 135). Isso o leva em direção à metapsicologia. Em 1937, na Análise terminável e interminável, Freud (1937/1970) evoca "a feiticeira metapsicologia". Podemos apenas dizer, afirma Freud: "So muss denn doch die Hexe dran! - a Metapsicologia da Feiticeira. Sem especulação e teorização metapsicológica - quase disse 'fantasiar' -, não daremos outro passo 
à frente" (Freud, 1937, p. 257). Infelizmente, complementa, o que a "Feiticeira" revela não é nem muito claro nem muito minucioso.

Assim, a ponta extrema da especulação metapsicológica coincide com a atividade, com a ação de fantasiar. Freud (1937) dela trata, vinculando-a ao especular (Speculieren) e ao teorizar (Theoresieren). Para Assoun (1983), essa aproximação mostra que o termo fantasiar, que Freud parece expor somente em 1937, ele já o utilizara desde a origem do trabalho de pensamento (Denkarbeit), 40 anos mais cedo, em seu Projeto para uma Psicologia cientifica, (Freud, 1895), para designar o essencial do processo psíquico. Ressalta-se que o Phantasieren metapsicológico atingiu o seu apogeu funcional em 1920, no texto Além do princípio de prazer (Freud, 1920), por ocasião do estabelecimento do conceito de pulsão de morte.

Os estudos de Assoun (1983) sobre os referentes epistêmicos nativos de Freud tornaram-se relevantes para examinar a estrutura e o corpus com os quais a metapsicologia freudiana lida. Nesse contexto, Laplanche e Pontalis (2016) esclarecem que "metapsicologia" foi um termo criado por Freud para designar a Psicologia por ele fundada, considerada na sua dimensão mais teórica. É importante destacar que, desde 1890, Freud não fazia outra coisa senão emitir considerações metapsicológicas, ficando, a palavra "metapsicologia" ligada à identidade freudiana, ou seja, às relações "dinâmica", "tópica" e "econômica": constitutivas do corpus metapsicológico. Assim, Freud distingue nitidamente o aspecto subjetivo do afeto e os processos energéticos que o condicionam. Inclusive, pode-se notar que, paralelamente ao termo afeto, em Alguns pontos para um estudo comparativo das paralisias motoras orgânicas e histéricas, de 1893, ele empregou a expressão "carga de afeto" (Affektbetrag) (Freud 1893a/1970, p. 238), designando, assim, o aspecto propriamente econômico: a quantidade, o quanto de afeto que ali se encontra presente, a tradução subjetiva da quantidade de energia pulsional. Em seus três ensaios sobre a teoria da sexualidade, Freud trata da questão da quantidade quando diz de um "quantum de libido" (Libidoquantum), e estabelece essa concepção, definitivamente, em $O$ inconsciente (Freud, 1915a/1970), quando aponta que se as representaçôes (Vorstellungen) são investimentos de traços mnêmicos, traços de memória (Erinnerungsspuren), os afetos são processos de descarga cujas manifestações finais são percebidas como sentimentos (Gefühlen) (Freud, 1915a, p. 204).

Mas, mesmo antes de 1915, ainda em relação aos rudimentos da transferência, Rabêlo et al. (2017) apontam como um dos referenciais que auxiliou Freud nos estudos metapsicológicos foi a Carta 52 para Fliess, de 6 de dezembro de 1896 (Freud, 1892-1899b/1970). Ali, ele destacou que o mecanismo psíquico se constitui por um processo de estratificação. Salientou que a memória é produzida 
e atualizada ininterruptamente pela interação de diferentes estamentos ou níveis de registros, cada um deles com uma sintaxe própria. Nessa carta, Freud destaca que a passagem de conteúdo de um nível para o outro pressupóe um complexo processo que envolve não apenas a inscrição de novos traços perceptivos, mas também retranscrições e traduções de conteúdos preexistentes. Destaca ainda que "o material presente sob a forma de traços mnêmicos fica sujeito, de tempos em tempo, a um rearranjo, de acordo com as novas circunstâncias - a uma retranscrição" (Masson, 1986, p. 208, grifo do autor). Por esse ângulo, o que ele considera de novo em sua teoria é "a tese de que a memória não se faz presente de uma só vez, e sim ao longo de diversas vezes, (e) que é registrada em vários tipos de indicações" (Masson, 1986, p. 208).

A Carta 52 permite descrever o fenômeno da transferência como o processo de tradução e atualização psíquica do trauma na relação com o analista. Freud (1892-1899b) descreve que os sucessivos registros representam a realização psíquica de épocas sucessivas da vida. Relata que, na fronteira entre essas épocas, deve ocorrer uma tradução, a nosso ver, uma espécie de transferência do material psíquico. Nessa carta, ele exemplifica seu raciocínio, referindo-se às peculiaridades das psiconeuroses; com a suposição de que essa tradução não se fez no caso de uma determinada parte do material, o que provoca determinadas consequências. Cabe ressaltar que Freud sustenta firmemente a crença numa tendência ao ajustamento quantitativo, o que desembocará em considerações importantes sobre o quantum contido na transferência.

Essa dimensão econômica também pode ser encontrada no Projeto para uma Psicologia cientifica (Freud, 1895). Como Ciência Natural, a Psicanálise deveria ser capaz de "representar os processos psíquicos como estados quantitativamente determinados de partículas materiais especificáveis, tornando assim esses processos claros e livres de contradição" (Freud, 1895, p. 315). Ao redigir o Projeto, ele assumiu a noção de quantidade: uma economia de forças. Dessa maneira, Freud realizou a transposição espaço-corpo, deslocando a investigação do corpo para o psiquismo, mantendo-o como ponto de vista metapsicológico primordial (Assoun, 1983).

Ainda no contexto desse aprofundamento, Rabêlo et al. (2017) destacam outra referência. Desta vez, a Carta 39 de Freud a Fliess, de $1^{\circ}$ de janeiro de 1896 (Freud, 1892-1899a/1970). Nela se encontra o sintagma "operaçóes de transferência” (Übertragungsvorgänge), utilizado para designar o fluxo livre de energia no sistema $p s i(\Psi)$, que constitui a característica principal do processo primário, próprio do sistema inconsciente. Freud esclarece que a energia livre tende a seguir os caminhos já previamente facilitados no sistema $p s i(\Psi)$. Segundo ele, existem três maneiras pelas quais os neurônios afetam uns aos outros: "(1) 
transferem quantidade de um para o outro; (2) transferem qualidade de um para o outro; (3) exercem um efeito excitante uns sobre os outros, de acordo com certas regras" (Masson, 1986, pp. 160-161).

Pode-se afirmar, portanto, que a representação $e$, para Freud, um dos elementos do processo psíquico, sendo o outro o afeto, uma tradução da quantidade de energia pulsional, como dito acima. Salienta-se que o termo Affekt não é um fato psíquico no mesmo plano da representação. Assim, faz-se necessário destacar que Freud acrescentou às representações outros fatores psíquicos (os afetos), e estes são a expressão qualitativa da quantidade de energia pulsional e suas variações. Para ele, toda a pulsão se exprime em dois registros: o do afeto e o da representação. Um exame global do trabalho metapsicológico freudiano reencontra esse eixo que permite organizar toda a dinâmica. Assim, Freud, aprofundou e teorizou essa perspectiva, afunilando a vida psíquica a esse alfabeto das representaçôes e dos afetos.

Laplanche e Pontalis (2016) esclarecem que a noção de afeto assume grande importância logo nos trabalhos de Breuer (1893) e de Freud (1893-1895) sobre a psicoterapia da histeria e a descoberta do valor terapêutico da ab-reação. A origem do sintoma histérico era procurada num acontecimento traumático a que não correspondia uma descarga adequada. Apenas se a evocação da recordação provocava a revivescência do afeto que estava ligado a ela em sua origem é que a rememoração encontrava a sua eficácia terapêutica. Para Laplanche e Pontalis (2016), da atenção e da reflexão de Freud sobre a histeria é que resulta a compreensão de que o afeto não estava necessariamente ligado à representação; sua separação (afeto sem representação, representação sem afeto) garante, então, a cada um diferentes destinos, indicando assim possibilidades de transformação do afeto: a conversão dos afetos (histeria de conversão), o deslocamento do afeto (obsessões) e a transformação do afeto (neurose de angústia, melancolia). A partir desse período, a noção de afeto é usada em duas perspectivas: ter apenas um valor descritivo e designar a ressonância emocional de uma experiência geralmente forte.

Freud trata essa questão de modo sistemático nos seus escritos metapsicológicos: Repressão (Freud, 1915c/1970) e O inconsciente (Freud, 1915a). O afeto foi ali definido como a tradução subjetiva da quantidade de energia pulsional. Assim, Freud distingue nitidamente o aspecto subjetivo do afeto e os processos energéticos que o condicionam. Inclusive, pode-se notar que, paralelamente ao termo afeto, ele empregou quantum de afeto (Affektbetrag), designando, assim, o aspecto propriamente econômico: a quantidade, o quanto de afeto que ali se encontra presente. 
A passagem de uma Psicologia introspectiva, fundada na observação interior, a uma Psicologia explicativa supóe o adicionamento da experimentação para se chegar a leis precisas, a partir dos fenômenos medir e pesar. Assim, peso e medida ingressaram na ciência psicológica, porque são eles que lhe conferem um caráter definitivo, condição epistemológica da maturidade. Por sua vez, quando Freud apresentou a noção do quantum, ele prolongou um problema preciso. Atestou aquilo sobre o qual toda a ciência psicológica pretendia discutir: um imperativo tão exigente quanto problemático, que se estabilizou na época em que Freud forjava sua metapsicologia.

\section{A IMPORTÂNCIA DE HERBART E FECHNER PARA A DINÂMICA REPRESENTACIONAL E PARA O INCONSCIENTE}

Além de apontarmos a linhagem dos fisiologistas alemães Brücke e Helmholtz como precursores da interação entre a Psicanálise, a Física e a Fisiologia, outro autor que serviu de base ao solo nativo de Freud foi Herbart (1776-1841), com o seu modelo de decifração do psiquismo (Assoun, 1983). Freud utilizou-se da referência herbartiana para destacar a importância do quantum energético da dimensão metapsicológica (um dos elementos constitutivos da transferência). Tal modelo foi construído na tradição da Psicologia de Herbart, dominante na Alemanha até meados do século XIX. Uma questão: até que ponto Freud, em sua concepção metapsicológica, tomou-a por referência e articulou-a ao fenômeno da transferência?

Registra-se que Herbart se propôs investigar a psiquê cientificamente, visto que ela tem seu átomo, sua moção de base nas representações. Herbart compreende que toda representação tem uma energia concomitante a ela. Tais representações apresentam um primeiro caráter visível: elas são, como forças, susceptíveis de medida, de quantificação.

A concepção herbartiana preconiza que as representações semelhantes se atraem e as diferentes se repelem. A associação de representaçôes semelhantes pode gerar uma terceira representação, enquanto as que, por algum motivo, não se associam podem se tornar esquecidas. Assim, as representaçóes antagônicas, por não se associaram, são passíveis de serem expelidas, pois as ideias mais fortes expelem as mais fracas. Quando duas representaçôes de natureza distinta se unem, denotase composição (Complexion); quando se trata de representaçôes de natureza idêntica, há fusão (Schmelzung). A partir dessa dupla combinatória básica, abre-se uma verdadeira lógica de reprodução representativa. Há reprodução imediata de uma representação quando o aparecimento de uma nova representação se opõe à representação antagonista que havia causado o obscurecimento da primeira: 
assim, esta fica liberada e pode reaparecer na consciência. Isso se torna possível a partir do momento em que a nova representação apresenta uma similitude com a antiga representação obscurecida.

Herbart chama de parada ou inibição (Hemmung) o processo pelo qual a representação se vê limitada em e por sua oposição a outra. Tal parada tem por efeito clivar a representação em duas partes: uma, que é transformada em "tendência", a outra, que subsiste como resíduo (Rest) mais ou menos enfraquecida. Ela passa, então, a ser definida por certo grau (Grad) de obscurecimento (Verdunkelung) da representação. Tal concepção se aproxima das ideias de Freud (1895), em seu Projeto para uma Psicologia científica, quando ele se refere à noção de recalque, como também quando aponta a dinâmica do psiquismo. Em síntese, uma ideia (pelo quantum de energia) pode, pelo mecanismo do esquecimento, expelir, censurar aquilo que representa.

Segundo Assoun (1983), a tomada em consideração da dinâmica representacional culmina em Herbart na implicação do inconsciente na vida psíquica. Nesse aspecto, uma representação estaria na consciência visto que não se encontra sujeita à "parada". O processo de obscurecimento "passa por um limiar (Schwelle), definido como estado de representação tal, que basta a menor ação para reconduzi-la à consciência" (Assoun, 1983, p. 152). Percebese a especificidade da associação herbartiana. Ela não é feita por uma simples contiguidade, por semelhança, como no associacionismo clássico, e sim, repousa num acontecimento, tendo por efeito modificar a dinâmica global das representações. Portanto não evoca outra representação de forças que tinha por efeito o ocultamento da antiga representação. Destaca-se que esse mecanismo possibilita uma analogia com o sistema pré-consciente freudiano, em sua dimensão topográfica.

Dessa maneira, evidencia-se que o modelo herbartiano tornou-se uma referência para a concepção freudiana, no qual se fez uma articulação à temática da transferência, com base numa leitura metapsicológica. Assim, constata-se a fecundidade dessa problemática para a análise freudiana da dinâmica das pulsões e das representações. Por isso mesmo, afirma-se a importância do modelo herbartiano na gênese de Freud, sua epistemologia rigorosamente nativa, e, portanto, uma referência em seu horizonte epistêmico. É importante destacar que quando Freud coloca na base da atividade psíquica a representação, ele reatualiza espontaneamente um esquema que lhe vem da Psicologia alemã inspirada em Herbart.

A investigação metapsicológica que enfatiza a questão energética baseada na Psicologia alemã oriunda de Herbart, com os seus os modelos de decifração 
representacionistas e energetistas do psiquismo, foi um dos esteios da posição de Freud no horizonte de seu tempo. Freud associou uma dualidade de base energética: energia livre e energia vinculada (sendo especificada na distinção de dois processos no psiquismo: primário - inconsciente e secundário - consciente). A distinção constituiu apenas a transposição de um par resgatado de numerosas teorias físicas e psicofisiológicas do século XIX: energia cinética/energia estática; energia atual/energia potencial. Para ele, a excitação tônica intracerebral desempenhou o papel de energia potencial, "oriunda de fontes nervosas, fisiológicas e psíquicas endógenas, que se transformou em energia cinética para alimentar as atividades efetivas do sistema nervoso" (Assoun, 1983, p. 205).

Mas é possível medir a energia? Como introduzir, sob sua forma matematizada mais rigorosa, a medida na vida anímica? Como é possível a quantitatividade do psiquismo? Qual a influência do quantum do psiquismo no comportamento? "Estas foram indagações e problematizações de Gustav Theodor Fechner, na ocasião em que a psicanálise freudiana entrava em sua fase de gestação - 1887" (Assoun, 1983, p. 161).

Fechner teve forte influência nas pretensões ulteriores da Psicologia científica e seu ativismo quantificador influenciou a construção da metapsicologia freudiana, assim como o foram os referentes herbartianos. Inclusive Fechner é citado por Freud em inúmeras ocasiōes. No texto $A$ interpretação dos sonhos (Freud, 1900), por exemplo, diz que foi ele quem ressaltou melhor a diferença essencial entre o sonho e a vigília: "Ninguém ressaltou com maior precisão a diferença essencial entre o sonhar e a vida de vigília, ou tirou dela conclusóes de maior alcance, do que G. T. Fechner, num trecho de sua obra Elemente der Psychophysik (1889, 2, 520-1)" (Freud, 1900, p. 78). Freud (1900) ressalta ainda que, para Fechner, a cena do sonho não é a mesma que aquela na qual se desenrolam as representações durante a vigília, chegando a colocar essa observação em itálico. Segundo Freud, Fechner "suspeita, antes, de que a cena de ação dos sonhos (seja) diferente da cena da vida de representaçôes de vigília" (Freud, 1900, p. 78, grifo do autor).

Assim pode-se dizer que Freud encontrou em Fechner uma antecipação da teoria do sonho e do inconsciente. Todavia, por detrás dessa intuição, há referências a uma concepção tópica e energética que Freud, em sua démarche, deu-se por tarefa aprofundar. Tal concepção apareceu no Projeto para uma Psicologia cientifica (Freud, 1895), implicada nas consideraçôes sobre o prazer e o desprazer. Como Assoun aponta, "Freud aí considerou uma certa tendência a evitar o desprazer, e o definiu como uma elevação da quantidade (Qn) ou aumento da tensão, e definindo o prazer como nascendo de uma sensação de descarga" (Assoun, 1983, p. 172). 
Finalmente é importante destacar que se pode, nessa investigação, situar Freud ao lado do energetismo mecanicista, dos processos energéticos. "Quer dizer que, a seus olhos, o que existe não é tanto a Energia, entidade maiúscula, quanto um tipo de processo agindo no psiquismo e etiquetado como energético" (Assoun, 1983, p. 205). Dessa forma, a posição de Freud aparece como decididamente energetista (o que abriu a pista fecunda para a análise do trabalho inconsciente, $o$ qual não cessou de explorar). Eis aí um marcador importante desta investigação. Foi por meio da noção de exigência de trabalho (Arbeitsforderung) que Freud (1915b/1970), em seu texto Os instintos e suas vicissitudes, caracterizou o fator da pulsão como uma pressão constante. No tangenciamento da dimensão econômica da metapsicologia define-se pulsão como um "conceito de fronteira entre o físico e o psíquico" (Freud, 1915b, p. 131). Eis a energética de Freud: no qual a pulsão impôs o inédito de seu objeto.

Pulsão! Só foi possível chegar a esse conceito ao se percorrerem os modelos e os referentes de Freud, indispensáveis para a compreensão das bases de seu fundamento metodológico, e consequente condição para o entendimento profícuo da gênese freudiana da transferência.

\section{CONSIDERAÇÕES FINAIS}

Este artigo tratou do tema da transferência, um dos conceitos fundamentais da clínica psicanalítica, e propôs localizar a démarche de Freud na gênese da construção desse conceito. Por esse motivo, escolheu-se, por meio de revisão bibliográfica, identificar a epistemologia de Freud; seus modelos e seus referentes físico-químico-energéticos.

Salienta-se que foi de grande valia a eleição do texto de Assoun, Introdução à epistemologia freudiana (Assoun, 1983), sobretudo articulado com os textos freudianos que trataram prioritariamente dos referentes epistêmicos de Freud e dos rudimentos da transferência. $\mathrm{O}$ uso de texto de outros autores também agregou valor a esta pesquisa.

Como resultado do percurso realizado, essa pesquisa atestou que a metapsicologia compôs as bases do fundamento metodológico de Freud, que, por sua vez, tornou-se uma das referências para o entendimento da gênese da transferência.

Esse estudo pode contribuir com as pesquisas que envolvem a temática da transferência, afirmando que este tem, em sua gênese, modelos e referentes localizados no solo nativo de Freud, indispensáveis à sua teorização. 


\section{REFERÊNCIAS}

Assoun, P. L. (1983). Introdução à epistemologia freudiana. Rio de Janeiro: Imago.

Barbelli, I. C. (2008). O estatuto epistemológico da Psicanálise freudiana: energética e hermenêutica. Dissertio, 27-28, 197-230.

Freud, S. (1892-1899a/1970). Extratos dos documentos dirigidos a Fliess. Carta 39. In J. Salomão (Trad.), Edição standard brasileira das obras psicológicas completas de Sigmund Freud. (Vol. 1, p. 400-421). Rio de Janeiro: Imago, 1970. (Publicado originalmente em 1892-1899).

Freud, S. (1892-1899b/1970). Extratos dos documentos dirigidos a Fliess. Carta 52. In J. Salomão (Trad.), Edição standard brasileira das obras psicológicas completas de Sigmund Freud. (Vol. 1, pp. 254-259). Rio de Janeiro: Imago, 1970. (Publicado originalmente em 1892-1899).

Freud, S. (1893a/1970). Alguns pontos para um estudo comparativo das paralisias motoras orgânicas e histéricas. In J. Salomão (Trad.), Edição standard brasileira das obras psicológicas completas de Sigmund Freud. (Vol. 1, pp. 217239). Rio de Janeiro: Imago, 1970. (Publicado originalmente em 1893).

Freud, S. (1893b/1970). A psicoterapia da histeria. In J. Salomão (Trad.), Edição standard brasileira das obras psicológicas completas de Sigmund Freud. (Vol. 2, pp. 253-294). Rio de Janeiro: Imago, 1970. (Publicado originalmente em 1893).

Freud, S. (1895/1970). Projeto para uma Psicologia científica. In J. Salomão (Trad.), Edição standard brasileira das obras psicológicas completas de Sigmund Freud. (Vol. 1, pp. 301-362). Rio de Janeiro: Imago, 1970. (Publicado originalmente em 1895).

Freud, S. (1900/1970). A interpretação dos sonhos. In J. Salomão (Trad.), Edição standard brasileira das obras psicológicas completas de Sigmund Freud. (Vol. 4, pp. 17-322). Rio de Janeiro: Imago, 1970. (Publicado originalmente em 1900).

Freud, S. (1914/1970). Observações sobre o amor transferencial: novas recomendações sobre a técnica da Psicanálise III. In J. Salomão (Trad.), Edição standard brasileira das obras psicológicas completas de Sigmund Freud. (Vol. 12, pp. 207-223). Rio de Janeiro: Imago, 1970. (Publicado originalmente em 1914).

Freud, S. (1915a/1970). O inconsciente. In J. Salomão (Trad.), Edição standard brasileira das obras psicológicas completas de Sigmund Freud. (Vol. 14, pp. 183244). Rio de Janeiro: Imago, 1970. (Publicado originalmente em 1915). 
Freud, S. (1915b/1970). Os instintos e suas vicissitudes. In J. Salomão (Trad.), Edição standard brasileira das obras psicológicas completas de Sigmund Freud. (Vol. 14, pp. 129-162). Rio de Janeiro: Imago, 1970. (Publicado originalmente em 1915).

Freud, S. (1915c/1970). Repressão. In J. Salomão (Trad.), Edição standard brasileira das obras psicológicas completas de Sigmund Freud. (Vol. 14, pp. 165182). Rio de Janeiro: Imago, 1970. (Publicado originalmente em 1915).

Freud, S. (1917/1970). Uma dificuldade no caminho da Psicanálise. In J. Salomão (Trad.), Edição standard brasileira das obras psicológicas completas de Sigmund Freud. (Vol. 17, pp. 166-179). Rio de Janeiro: Imago, 1970. (Publicado originalmente em 1917).

Freud, S. (1919/1970). Linhas de progresso na terapia psicanalítica. In J. Salomão (Trad.), Edição standard brasileira das obras psicológicas completas de Sigmund Freud. (Vol. 17, pp. 199-220). Rio de Janeiro: Imago, 1970. (Publicado originalmente em 1919).

Freud, S. (1920/1970). Além do princípio de prazer. In J. Salomão (Trad.), Edição standard brasileira das obras psicológicas completas de Sigmund Freud. (Vol. 18, pp. 13-85). Rio de Janeiro: Imago, 1970. (Publicado originalmente em 1920).

Freud, S. (1925/1970). Um estudo autobiográfico. In J. Salomão (Trad.), Edição standard brasileira das obras psicológicas completas de Sigmund Freud. (Vol. 20, pp. 13-92). Rio de Janeiro: Imago, 1970. (Publicado originalmente em 1925).

Freud, S. (1926/1976). Inibições, sintomas e ansiedade. In J. Salomão (Trad.), Edição standard brasileira das obras psicológicas completas de Sigmund Freud. (Vol. 20, pp. 96-200). Rio de Janeiro: Imago, 1976. (Publicado originalmente em 1926).

Freud, S. (1937/1970). Análise terminável e interminável. In J. Salomão (Trad.), Edição standard brasileira das obras psicológicas completas de Sigmund Freud. (Vol. 23, pp. 241-287). Rio de Janeiro: Imago, 1970. (Publicado originalmente em 1937).

Freud, S. (1938/1976). Esboço de Psicanálise. In J. Salomão (Trad.), Edição standard brasileira das obras psicológicas completas de Sigmund Freud. (Vol. 23, pp. 165-198). Rio de Janeiro: Imago, 1976. (Publicado originalmente em 1938). 
Freud, S. (1940/1970). Algumas lições elementares de Psicanálise. In J. Salomão (Trad.), Edição standard brasileira das obras psicológicas completas de Sigmund Freud. (Vol. 23, pp. 315-321). Rio de Janeiro: Imago, 1970. (Publicado originalmente em 1940).

Laplanche, J., \& Pontalis, J. B. (2016). Vocabulário de Psicanálise. São Paulo: Martins Fontes.

Masson, J. (1986). A correspondência completa de Sigmund Freud para Wilhelm Fliess. Rio de Janeiro: Imago.

Rabêlo, F. C., Veras Filho, C. J. C., Danziato, L., \& Quadros, R. B. S. (2017, janeiro-março). Os fundamentos da técnica da transferência de 1895 a 1905. Psicologia, Ciência e Profissão, 37(1), 132-145. 